\title{
Primate empathy: A flexible and multi-componential phenomenon
}

\author{
Jake S. Brooker ${ }^{a}$, Christine E. ${ }^{b}$ Webb \& Zanna Claya \\ a Department of Psychology, Durham University, South Road, Durham DH1 3LE, \\ UK \\ ${ }^{b}$ Department of Human Evolutionary Biology, Harvard University, 11 Divinity \\ Avenue, Cambridge, MA 02138, USA \\ Correspondence: zanna.e.clay@durham.ac.uk; jake.s.brooker@durham.ac.uk \\ This chapter is currently in press and will be published at Cambridge University \\ Press in the volume "Primate Cognitive Studies", edited by Michael J. Beran and \\ Bennett L. Schwartz.
}

Please use the following citation:

Brooker, J. S., Webb, C. E. and Clay, Z. (in press). Primate empathy: A flexible and multi-componential phenomenon. In B. L. Schwartz \& M. J. Beran (Eds.), Primate Cognitive Studies. Cambridge University Press. 


\section{Abstract}

Empathy, the capacity to share and understand others' states, is crucial for facilitating enduring social relationships and managing ingroup and outgroup dynamics. Despite being at the center of much scrutiny and debate in human research, the evolutionary foundations of empathy remain relatively opaque. Moreover, inconsistencies remain regarding definitions and theoretical models, leading to discrepancies in how to systematically represent and address empathy and understand its evolutionary basis. As a complex, multi-dimensional phenomenon, certain components of empathy are likely to be evolutionarily ancient whereas others may be more derived. As our closest living relatives, nonhuman primates provide an opportunity to explore the evolutionary origins of empathy and its subcomponents. Due to the rich diversity of primate societies, we can comparatively study evidence of affective responding and empathic behaviour within the context of different social dynamics and organisation. Although studies have been conducted on individual primate species, especially the great apes, direct species comparisons are rare. Here we examine the literature investigating evidence for empathy among primates focussing on its underlying affective and cognitive components. In reviewing the literature, we also highlight species that need more coverage to enhance our overall understanding of how empathy has evolved within the primate order.

\section{Keywords}

Mimicry; emotional contagion; consolation; perspective-taking; great ape; affect; social cognition 


\section{Introduction}

\subsection{General}

Empathy is broadly defined as the ability to recognize and understand others' emotions and states (Cuff et al., 2016); which enables situation-specific prosocial interactions that aid the establishment and maintenance of social bonds (Preston \& de Waal, 2002). Empathy is believed to incorporate automatic and conscious responses, where affective reactions to emotional stimuli are modulated by top-down cognitive processes (Cuff et al., 2016). Trait and state influences can mediate empathic reactions, resulting in individual variation in the strength or presence of an empathic response (Eisenberg et al., 1999; Webb et al., 2017).

Comparative research has uncovered many socio-cognitive abilities in animals originally considered exclusive to humans, including culture, tool-use, and complex communication (e.g., van Schaik et al., 1999). Although research into animal emotions is relatively recent, empathy has been reported across diverse mammal species ranging from elephants (e.g., Plotnik \& de Waal, 2014) to small rodents (e.g., Burkett et al., 2016). Empathic behaviour has also been documented in some avian species (e.g., corvids, Corvus corax; Fraser \& Bugnyar, 2010), indicating that empathy may have flexible origins, emerging when social attachment and parental care are key (MacLean, 1985).

Thus far, the largest body of research on empathy and its related components has focused on non-human primates (henceforth primates). This work is especially concentrated on our closest relatives, the great apes (Clay et al., 2021), with monkeys and prosimians understudied by comparison. Given their phylogenetic proximity to humans, studying empathy in primates can illuminate the social and ecological conditions promoting the evolution of empathy. Applying systematic comparative methods in various primates may reveal which components of empathy emerged in 
specific species or genera due to different selective pressures and social dynamics. Moreover, measuring different types of empathic responses within the same study species may yield deeper insights into which components of empathy manifest independently and are proximately or functionally linked.

In this chapter, we describe how empathy appears to manifest as a multidimensional trait, outline how each component may be studied empirically, and then discuss existing findings from primates. We compare these to findings from human research to provide evolutionary context. We explain why more cross-species comparisons are needed to understand the social and ecological drivers of empathy's evolution as well as the extent of its variability across species. Studying the empathic capacities of other

primates allows us to identify the evolutionary roots of human socio-emotional skills and cognition, and how such behaviours evolved in our ancestral lineage and are shared. In particular, observing humanity's closest extant relatives, the great apes, can help us identify when certain traits and behavioural elements may have emerged uniquely in our evolutionary history, versus those that are shared and evolutionarily ancient.

\subsection{The conceptualisation of empathy}

Empathy is considered a multi-dimensional phenomenon comprising multiple cognitive and affective sub-components (de Waal, 2007). Discrepancies in definitions have created dissonance in studying empathy as many scholars have emphasized unique components of empathy or posited different linkages amongst empathy's diverse components (Cuff et al., 2016). Generally, all definitions consider empathy as an ability to perceive and/or understand the emotion of another individual, which may trigger a prosocial response in cases of distress. Many empirical definitions of empathy are borne out of human psychological research and do not traditionally ascribe such emotion responsiveness to animals. In recent years, however, comparative approaches have attempted to conceptualise empathy as it manifests across species. 
A leading theoretical model to explain empathy across animal societies is the Perception-Action Model (PAM; Preston \& de Waal, 2002). According to the PAM, one perceives an external state or physical action that evokes representations of this state/action in oneself. This can result in physiological reactions such as body surface temperature changes (Ebisch et al., 2012) and behavioural responses to provide relevant or appropriate assistance (Lindegaard et al., 2017). The 'Russian Doll' Model (de Waal, 2007) builds on this framework by likening the perception-action mechanism to empathy's core, representing the most basic emotional reactions such as mimicry and contagion. Around this core are layers of increasing cognitive and affective complexity, where more complex other-oriented responses are functionally integrated with underlying affective processes, thereby facilitating behaviours including targeted helping and consolation.

To move beyond definitional discrepancies, we describe empathy broadly in this chapter as a multidimensional system comprising affective and cognitive sub-components, in line with Preston and de Waal (2002) and de Waal and Preston (2017). Subcomponents of empathy - including matching and understanding others' emotional states and responding prosocially - can be empirically targeted and we discuss relevant findings from studies addressing these. Although involuntary behaviours such as mimicry and behavioural contagion are implicated in social affiliation and may indicate other-oriented sensitivity, they themselves appear to be distinct phenomena which may contribute to empathy. This segmental approach means that we can study these traits individually and collectively in humans and other animals, including primates, to examine the evolutionary drivers for empathy.

\section{Studying the basis for empathy in primates}

In line with the Russian Doll Model (de Waal, 2007), we describe six areas of study referring to components of empathy observed in primates. We start with those reflecting 
the most basal expressions including mimicry, behavioural contagion, and emotional contagion, up to the proposed 'outer layers' of the Russian Doll consisting of three related but distinct components: perspective taking, consolation, and targeted helping.

\subsection{Mimicry}

Although emotional responses can involve conscious decision-making, they frequently occur automatically (Lamm et al., 2007). Mimicry is the involuntary copying of another's physical appearance and may constitute the synchronisation of movements, body posture, facial expressions, or vocalisations (Chartrand \& Bargh, 1999). Mimicry has often been included in descriptions of emotional contagion, the matching of another's internal state leading to emotional synchrony (Hatfield et al., 1993). Whilst facial mimicry is common when emotional expressions are observed, there is conflicting evidence for a direct link between mimicry and subsequent experiences of the presumed underlying affective state in humans (Hess \& Blairy, 2001; van der Schalk et al., 2011). Furthermore, facial mimicry studies in various species have often collated congruent motor action with congruent internal states (Adriaense et al., 2020), but such uncontrollable quick reactions cannot alone represent emotional contagion or a complex phenomenon such as empathy.

Although the link between mimicry and emotion contagion remains unresolved, mimicry has been proposed to have emerged as a prerequisite for more complex social and emotional behaviours (de Waal, 2007; de Waal \& Preston, 2017). For instance, mimicking or copying the actions of others can help immature individuals learn the correct contexts and usage for particular behaviours (Want \& Harris, 2002) and promote affiliative relationships (e.g., Paukner et al., 2009). Thus, whilst it may not require an affective basis, due to its importance in affiliative bonding, mimicry (along with emotional contagion) may be considered a component within the foundational building blocks towards empathy. Next, we describe some of the findings from primate mimicry studies. 


\subsubsection{Mimicry in primates}

Face-to-face interactions are important features of many primate social relationships (Dettmer et al., 2016) and affect-matching behaviours like facial mimicry may enable social bonding and reflect relationship quality (Palagi et al., 2014). Neonatal mimicry of adult facial displays, akin to human neonate studies by Meltzoff and Moore (1977; but see Davis et al., 2021), has been seen in small samples of neonatal chimpanzees (e.g., Myowa, 1996; Myowa-Yamakoshi et al., 2004). Similar to human findings, mimicry responses disappeared after two months (Myowa, 1996; Myowa-Yamakoshi et al., 2004). Rhesus macaques, a cercopithecine monkey species, also appear to mimic tongue protrusion and the species-typical affiliative lip-smacking facial gesture in the first days of life, with mimicry waning by the seventh day of life (Ferrari et al., 2006).

Much of the literature on mimicry in primates has targeted rapid and delayed mimicry of play-faces. The primate play-face is considered homologous to human facial laughter and evocative of positive affective states in the perceiver (Parr \& Waller, 2006). As this facial expression may reveal an explicit affective state that is easily interpreted and can trigger matching reactions in conspecifics, play-face mimicry is believed to honestly convey a positively valence intention, thereby reducing the possibility that a conflict will arise (Palagi, 2018). Rapid facial mimicry (RFM) - i.e. mimicry of facial expressions occurring within one second of perception, indicating instinctive responsiveness - has primarily been observed during great ape play interactions (chimpanzees: Palagi et al., 2019; western lowland gorillas: Palagi et al., 2019; Bornean orangutans: Davila-Ross et al., 2008), as well as a cercopithecine monkey, the gelada (Theropithecus gelada; Mancini et al., 2013). Mimicry may assist the development of social competence in young primates by facilitating the capacity to properly distinguish playful intentions during rough play that can involve faux aggressive behaviour (Palagi, 2018). Beyond play, RFM is also associated with longer sexual contacts in homosexual and heterosexual bonobo (Pan paniscus) interactions, particularly among female-female dyads (Palagi et al., 2020). Mimicry in these contexts may therefore help to strengthen social relationships and increase reproductive potential. 
Beyond facial mimicry, motor mimicry of conspecifics has been seen in observational learning experiments, whereby observation of social cues and actions can facilitate copying (Hopper et al., 2008). Lab-housed capuchin monkeys (Cebus apella) have been observed replicating the motor actions of fellow group members when opening artificial foraging devices (Dindo et al., 2009). Similar findings have been reported in chimpanzees synchronising their movements with conspecific models during tool use learning (Fuhrmann et al., 2014).

Neverthless, the extent to which mimicry and empathy are related remain equivocal, even in human studies. Involuntary facial mimicry has been associated with higher selfreported measures of empathy in humans (Dimberg \& Thunberg, 2012), but not cognitive appraisal of observed emotions (Sonnby-Borgström, 2002). Furthermore, facial mimicry and perception of natural emotional expressions appear to activate neural regions associated with motor and emotional processing in humans (Rymarczyk et al., 2018). Despite many studies suggesting a link between mimicry and empathy (Adriaense et al., 2020), clear evidence of a physiological or behavioural emotional response has not yet been demonstrated (Isern-Mas \& Gomila, 2019). In primates, this potential link has yet to be directly explored.

\subsection{Behavioural contagion}

Behavioural contagion, defined as an individual engaging in an unlearned behaviour that automatically triggers a similar behaviour in others (Zentall, 2003), has been observed in humans and other primates (Amici et al., 2014). Mimicking presumably unlearned facial expressions is typically not described as behavioural contagion despite generally fitting the above definition, aside from yawn contagion (Campbell \& de Waal, 2011). Behavioural contagion is generally reserved for motor mimicry of specific selfdirected or social actions. Examples observed in primates include scratching (Feneran et al., 2013), grooming, and scent-marking (Massen et al., 2016). 
Yawn contagion, whereby the observation of one individual yawning in a relaxed context triggers a matched response in the observer, is prevalent in humans and some primates, and has been studied in naturalistic and experimental settings (Massen \& Gallup, 2017). Yawning has been purported to have physiological functions, including increasing oxygen intake to the blood and brain (e.g., Baenninger, 1997), as well as social functions, such as forming part of affiliative communication with other group members (see Leone et al., 2014 for an example in female geladas). Yawning is highly contagious in adult humans to the point that instruction to think or read about yawning is enough to induce a yawn (Provine, 1986). Contagious facial displays such as yawning have also been defined as facial mimicry in the literature (Norscia et al., 2016); however, we include it as behavioural contagion as it includes additional motor and auditory components.

Due to links with emotional affinity and perspective-taking, some types of behavioural contagion have been posited to reflect empathy (e.g., Platek et al., 2003). In both visual and auditory yawn contagion studies, contagion appears to be stronger among human dyads with strong social bonds (Norscia et al., 2016). Furthermore, neuroscientific research indicates that viewing yawning activates neural regions associated with selfprocessing and theory-of-mind (Massen \& Gallup, 2017), strengthening the claim of an association with other-oriented processes.

However, more evolutionarily-ancient systems may be responsible for contagious yawning that are not associated with empathy; notably, it is difficult to determine a caught yawn compared to a spontaneous yawn, especially when some individuals are more likely to yawn spontaneously than others (Massen \& Gallup, 2017). Additionally, yawns may only appear to be contagious because experimental designs pick up perceptual pattern recognition errors (Kapitány \& Nielsen, 2017). Regardless, contagious yawning remains the primary approach to studying behavioural contagion in humans and other animals. Here we review primate studies in the contagion of various behaviours, including yawning, scratching, grooming, and other social behaviours. 


\subsubsection{Behavioural contagion in primates}

Contagious yawning has thus far been observed in chimpanzees (Campbell \& de Waal, 2011), bonobos (Demuru \& Palagi, 2012), Bornean orangutans (van Berlo et al., 2020), geladas (Palagi et al., 2009), and stumptailed macaques (Macaca arctoides; Paukner \& Anderson, 2006). Among prosimians, contagious yawning has only been tested in two strepsirrhines, ring-tailed lemurs (Lemur catta) and black-and-white ruffed lemurs (Varecia variegata), where it was reported as absent (Reddy et al., 2016). It has been suggested that, among primates, contagious yawning may be exclusive to haplorrhines, though not omnipresent.

Behavioural contagion appears to be stronger between close social partners (Demuru \& Palagi, 2012; Palagi et al., 2009; Palagi et al., 2014), indicating a possible association with empathy (de Waal, 2008; Palagi et al., 2009). According to this hypothesis, one would expect contagious yawning to be absent for species that do not have strong affiliative tendencies. Accordingly, yawn contagion was shown to be absent in a group of captive western lowland gorillas during naturalistic and experimental paradigms (Palagi et al., 2019). Gorillas are characterised by low social affiliation despite living in groups. However, despite their semi-solitary lifestyles, yawn contagion has been reported among Bornean orangutans (van Berlo et al., 2020). Although this result may be due to social affiliation artificially enhanced by captivity, it suggests that social closeness and yawn contagion may be functionally linked.

Beyond yawning, other contagious behaviours have rarely been investigated in primates. Recent research investigated grooming contagion among rhesus macaques, whereby individuals initiated independent grooming sessions themselves faster after observing other individuals grooming, compared to control periods (Berthier \& Semple, 2018; Ostner et al., 2021). Furthermore, scratching appears to facilitate matched responses in rhesus macaques (Feneran et al., 2013) and Bornean orangutans (Laméris et al., 2020). Interestingly, in these studies, contagion was not more likely 
when viewing familiar individuals, suggesting alternative underlying mechanisms than empathy, such as anxiety when viewing outgroup individuals.

Although there is no evidence yet of yawn contagion in platyrrhines, other possible contagious behaviours have been studied in two family groups of lab-housed common marmosets (Callithrix jacchus; Massen et al., 2016). Whilst yawning and stretching were rare, gnawing and scent-marking behaviours were temporally clustered indicating contagion. Over $75 \%$ of all scent-marking behaviour was observed within the 20 seconds following matched scent-marking from a neighbouring individual. Such coordination may have territorial benefits by enhancing their collective signal and quickly communicating to conspecific group members.

In summary, while there is evidence of behavioural contagion, there remains scepticism regarding its links to empathy as alternative explanations, such as stress-relief, should be considered (Feneran et al., 2013). As in humans, some behavioural contagion is stronger if the subject has a strong social bond with the model stimulus (e.g., Demuru \& Palagi, 2012). However, some captive reports (e.g., Massen et al., 2012; van Berlo et al., 2020; Feneran et al., 2013) indicate no such pattern. Furthermore, with the discrepancy in observed latency times across contagion studies, from 20-40 seconds (Massen et al., 2016) to 5 minutes (Palagi et al., 2009), issues of standardization and replicability become more prominent.

\subsection{Emotional contagion}

Emotional contagion refers to the matching of another's emotional state, triggering similar arousal states in oneself (Hatfield et al., 1993). Whether or not true emotion contagion has occurred (i.e., the contagion of the same state in the observer as the actor), many behaviours in humans and animals appear to be driven by underlying states that are triggered through observing the states of others (Chotard et al., 2018; Provine, 1992). Buchanan et al. (2012) found that in human participants, salivary 
hormones associated with internal stress, cortisol and alpha-amylase, increased when observing other people undertaking stressful tasks. Furthermore, this was associated with self-reported empathic concern and perspective-taking abilities.

Emotional contagion has been studied with both positively and negatively valenced stimuli by exposing subjects to conspecifics experiencing rewarding social and food events or aversive social isolation events respectively (e.g., Reimert et al., 2017). The evaluation of these underlying responses in the absence of behavioural reactions elucidates how emotional expressions of others can affect the internal state of independent observers. However, it is notoriously difficult to determine emotion occurrences in all species, including humans, and many emotional states lack clear physiological and behavioural signatures. Some emotional expressions do however show such signatures and recent innovative approaches to measure internal state changes have indicated some emotional contagion in humans and primates.

One such approach to understand the physiological basis of emotion contagion is infrared thermography (IRT). This non-invasive contact-free approach enables reliable detection of activity of the autonomic nervous system across species by measuring skin temperature changes upon exposure to particular affective stimuli (Speakman \& Ward, 1998). Human research has indicated facial skin temperatures can change in response to different social contexts including affect-matching in mothers and their children during specific emotional situations such as infant distress (Ebisch et al., 2012). Thus far, the core regions of interest for IRT include the nasal, perinasal, orbital, periorbital, and maxillary regions of the face in IRT research. In particular, negative valence stimuli, such as stressful social stimulations, are associated with drops in nasal and maxillary area temperatures (loannou et al., 2014). Evidence in primates is discussed below.

\subsubsection{Emotional contagion in primates}


Skin temperature changes following exposure to emotional stimuli have been recorded in several primate species, including pigtailed macaques (Macaca nemestrina; Baker et al., 1976), chimpanzees (Dezecache et al., 2017; Kano et al., 2016), common marmosets (Chotard et al., 2018), white-throated capuchins (Cebus capucinus; Chotard et al., 2018), rhesus macaques (Chotard et al., 2018), Bornean gibbons (Hylobates muelleri; Chotard et al., 2018) and western lowland gorillas (Chotard et al., 2018).

Homologous to humans (loannou et al., 2013), primate nasal skin temperature in generally drops in response to negatively valenced stimuli (macaques: Nakayama et al., 2005; Kuraoka \& Nakamura, 2011; chimpanzees (Dezecache et al., 2017; Kano et al., 2016). Dezecache et al. (2017) found significant drops in ear and nose surface temperatures of wild chimpanzees in response to hearing naturally occurring conspecific vocalisations, particularly to aggressive barks in conflict contexts (Dezecache et al., 2017). Decreased skin temperature and increased tympanic membrane temperature have also been demonstrated in captive chimpanzees responding to emotional video images (Parr, 2001).

Another physiological measure of emotional contagion is pupil mimicry, achieved by measuring matching of pupil dilation between two individuals engaged in an interaction (Bradley et al., 2008). This involuntary, automatic response is associated with increased attention and arousal and has been paired with activity in social brain regions (Prochazkova et al., 2018). In a comparative study, chimpanzees and humans observed videos of both species with dilated or constricted pupils, and both species were shown to mimic pupil dilation of conspecifics (Kret et al., 2014). Whilst the chimpanzee sample size and effects were limited, this study suggests that pupil-mimicry may facilitate instantaneous communication of internal states.

In sum, although techniques such as IRT and pupil mimicry can assist in elucidating the basis of emotional contagion in animals, contextual cues are important to consider. For instance, particular stimuli - such as observing social conflicts (Kano et al., 2016) or seeing threatening objects such as needles (Parr, 2001) - may trigger aversive 
reactions in the subject that are unrelated to observing a conspecific's emotional state but instead relate to one's own personal negative memories. Such responses have been observed in chimpanzees that appeared to become physiologically aroused, measured through decreased nasal temperature, upon sight of an experimenter's injury without corresponding vocal or visual distress (Sato et al., 2019). Similar responses to emotional stimuli are seen in humans and other primates (Dezecache et al., 2017), indicating possible physiological homology between humans and primates. For nonverbal species, researchers may be able to further apply such innovative physiological recording methods to assess potential affect matching in response to experiencing other individuals' emotions or states.

\subsection{Perspective-taking}

Theory of Mind (ToM) - the ability to ascribe mental states to others (Premack \& Woodruff, 1978) - has been the focus of much research and debate, in humans and other primates in particular (Krupenye \& Call, 2019). Considered a mental process enabling one to take another's perspective and relate to their own emotions, thoughts, and intentions (Decety \& Svetlova, 2012), self and other's states, which can facilitate more complex forms of empathy (Batson et al., 1997). In humans, imagining how another person feels during a period of need has been shown to increase altruistic motivation in observers, whilst imagining being in their position increases personal distress and egoistic behaviour (Batson et al., 1997). Self-awareness and recognition of one's own mental state may allow one to feel and recognise another's emotional state whilst understanding the accurate source of this internal state shift. Such cognitive appraisal of an individual's specific need is thought to enable offering targeted assistance to particular situations (de Waal, 2008).

Although the extent of ToM in animals is debated, there is nevertheless evidence that many of its sub-components have deep evolutionary histories. The amalgamation of comparative cognition research indicates that ToM is composed of a suite of interacting 
cognitive and regulatory mechanisms. As perspective-taking abilities appear to exist in nonhuman species, ToM doesn't appear to fully depend on language or human unique forms of culture (Krupenye \& Call, 2019). In this volume, Lewis and Krupenye (chapter XX) comprehensively review primate perspective-taking research, explaining the history of the field, appropriate methodologies and empirical findings. Thus, this part of our chapter only focuses on the implications of perspective-taking research for studying emotions and empathy in primates, particularly in regard to how ToM may facilitate empathic behaviour such as consolation and targeted helping.

\subsubsection{Perspective-taking in primates}

Captive chimpanzees show evidence of understanding conspecifics' goals (Yamamoto et al., 2012) and what individuals can and cannot see (Hare et al., 2000). Bonobos may be more adept than chimpanzees in ToM-related tasks and understanding social causality, as evidenced by higher scores in tasks on gaze following and understanding others' goals and intentions (Herrmann et al., 2010). Although ToM has been assumed to be less well developed in non-ape primates (Call \& Tomasello, 2008), several paradigms have challenged this view by indicating the presence of visual perspectivetaking in common marmosets (Burkart \& Heschl, 2007), spider monkeys (Ateles geoffroyi; Amici et al., 2009), capuchin monkeys (Cebus appella; Amici et al., 2009), long-tailed macaques (Macaca fascicularis; van den Berg et al., 2012), Tonkean macaques (Canteloup et al., 2016), and Diana monkeys (Cercopithecus diana; Scerif et al., 2004).

Overduin-de Vries et al. (2014) applied an adjusted food competition paradigm to examine ToM with long-tailed macaques based on a seminal study by Hare et al. (2000) with chimpanzees. Subordinate macaques viewed two food sources in the presence of a dominant; one was displayed as visible to both parties, whereas the other was only visible to the observer. Subordinates tended to select food items that were not visible to dominants. Building on this finding, a recent study on free-living juvenile rhesus 
macaques found preliminary evidence for visual perspective tracking of human agents and making subsequent predictions on these observations (Arre et al., 2020).

Thus, despite previous assumptions, numerous monkeys and apes appear capable of comprehending the psychological states of others. To examine whether social complexity may be the causal factor in explaining the presence of this ability in certain primates, researchers compared social perspective taking skills in ring-tailed lemurs, which live in large multi-male/multi-female communities, to other lemurs that live in relatively smaller groups (MacLean et al., 2013; Sandel et al., 2011). As predicted, ringtailed lemurs outperformed other lemurs (Eulemur fulvus; Eulemur macaco; Eulemur mongoz; Varecia variegata) and sifakas (Propithecus coquereli) in gaze-following (Sandel et al., 2011) and visual perspective-taking tasks (MacLean et al., 2013). As ring-tailed lemurs significantly outperformed their close genetic relatives, convergence in these abilities with haplorrhines may be due to their similarly large and/or complex societies, and increased social exposure and demand.

While primate research has predominantly focused on visual perspective-taking, there has also been some research into the auditory sphere (Bray et al., 2014; Melis et al., 2006). Chimpanzees (Melis et al., 2006) and rhesus macaques (Santos et al., 2006) appear capable of understanding what other individuals can or cannot hear. Both species were presented with food in "noisy" containers, which would alert anyone nearby to interference, and "silent" containers, which could be opened discreetly. Both species preferred to obtain food from the silent containers when human experimenters were present but facing away from the containers. Ring-tailed lemurs, tested on a similar paradigm, were more likely to steal food when they could not be seen by an experimenter, but they did not show a preference for the silent container indicating that they may not have been sensitive to what the experimenter could hear (Bray et al., 2014).

In sum, many nonhuman primates appear to possess some levels of visual and/or auditory perspective-taking. Crucially, although these observations do not equate to 
empathy, they nevertheless do provide a foundation for some of the cognitive components of empathy, including comprehending others' states and how they differ from their own. This capacity insight may facilitate other empathic behaviours such as consolation and targeted helping, which appear to be specific behavioural responses to certain needs. Consolation and targeted helping are described over the next two sections.

\subsection{Consolation}

Consolation, or unsolicited post-conflict affiliation by uninvolved bystanders towards distressed victims (de Waal \& van Roosmalen, 1979), has often been taken as a marker of empathy in animals (de Waal \& Preston, 2017). Ascribing an empathy explanation to this behaviour typically requires first ruling out alternative explanations, such as the bystander gaining direct selfish benefits (like reduced risk of aggression) as well as showing the affiliation to be socially-targetted and that is has stress-relieving effects on the recipient.

Across species, consolation has been studied extensively in humans and animals including in children as young as 2 years old (Zahn-Waxler \& Radke-Yarrow, 1990), elephants (Plotnik \& de Waal, 2014), marine mammals (Yamamoto et al., 2015), rodents (Burkett et al., 2016), and avians (Fraser \& Bugnyar, 2010). Consistent with the proposal that empathy is socially-biased, consolation is more likely to be directed towards individuals with whom the actor shares a close relationship; this tendency is already evidenced in the consolation by young human children (ZahnWaxler \& Radke-Yarrow, 1990) as well as that of other animals, described more below.

\subsubsection{Consolation in primates}


Among primates, post-conflict consolation of distressed victims has been demonstrated thus far in chimpanzees (Fraser et al., 2008; Webb et al., 2017), bonobos (Clay \& de Waal, 2013), gorillas (Cordoni et al., 2006; Mallavarapu et al., 2006), Tonkean macaques (Palagi et al., 2014), and hamadryas baboons (Papio hamadryas; Butovskaya et al., 2015). In all of these cases, consolation is predicted by a close social relationship between the consoler and the victim, consistent with an empathy based explanation. Similar to the comforting contacts observed in humans, primate consolation behaviours commonly include embracing, gentle touching, stroking and patting (de Waal \& van Roosmalen, 1979; Lindegaard et al., 2017); although in bonobos, sexual forms of consolation are also common (de Waal, 1988).

Thus far, while consolation has received broad attention from comparative researchers, most findings have come from captivity. Although this is largely due to the challenge of reliably detecting post-conflict contacts in the wild, which can be rarer and harder to see, it remains unclear whether consolation is ubiquitous among wild individuals and all ape species. Among wild great apes, only one study with chimpanzees has reliably demonstrated consolation (Arnold \& Whiten 2001). In gorillas, although captive western lowland gorillas have been observed offering both solicited and unsolicited post-conflict affiliation (Cordoni et al., 2006), predominantly through social proximity (Mallavarapu et al., 2006), free-living mountain gorillas (Gorilla gorilla berengei) only provided postconflict affiliation when solicited by victims (Watts, 1995).

Although bystanders may approach to offer friendly contacts to distressed victims, research has also shown that such contacts may fulfil other functions and be driven by other proximate mechanisms unrelated to empathy. In a study of stump-tailed macaques, Call et al. (2002) found post-conflict third-party affiliation only limited further aggression by the victim, and thus did not refer to these contacts as consolatory due to a lack of victim anxiety reduction. Similarly, Schino and Marini (2012) found that thirdparty affiliation in mandrills (Mandrillus sphinx) did not reduce victim anxiety and were not associated with dyadic social closeness. 
Consolation is also not a feature in all primate societies. In contrast to the positive cases described above, consolation has been reported as absent in Japanese macaques (Macaca fuscata; Palagi et al., 2014), rhesus macaques (Matheson, 1999); brown capuchin monkeys (Verbeek \& de Waal, 1997), ring-tailed lemurs, and redfronted lemurs (Eulemur fulvus rufus; Kappeler, 1993). Captive brown capuchins engaged with conflict participants significantly less after a conflict than usual (Verbeek $\&$ de Waal, 1997). Despite early research indicating consolation to be absent in captive barbary macaques (Macaca sylvanus; Aureli et al., 1994), McFarland and Majolo (2012) found evidence for the behaviour. Consolation occurred primarily between close social partners, but contact appeared to have no subsequent effect on the victim's behavioural anxiety levels. In stump-tailed macaques (Call et al., 2002) and mandrills (Schino \& Marini, 2012), bystanders were shown to offer friendly contact, however victim anxiety did not appear to reduce in either species making its underlying function ambiguous.

According to the 'Social Constraints Hypothesis' (de Waal \& Aureli, 1996), consolation is strongly predicted by the degree of tolerance within a given species' social structure. In socially tolerant species or groups, risks of further aggression for potential bystanders are lower and therefore bystanders should be expected to approach more readily (Fraser et al., 2009). Consisent with this, Palagi et al. (2014) reported stress-relieving effects of consolation in Tonkean macaques, considered to be among the most tolerant macaque species; whereas consolation in the more despotic Japanese macaque was absent. Tonkean macaque consolation fulfilled other criteria for consolation, incuding being biased towards close social partners and reducing victim anxiety, as measured by self-scratching.

While bystander-solicited affiliation may have consolatory functions to the receipients, it can provide other benefits; including substituting for reconciliation, whereby the bystander reconciles on behalf of the opponent, with whom they share a close relationship. A developmental study found reconciliation and consolation increased significantly in 5-year-old human children, compared to 3- and 4-year-olds, and consolation more often occurred when no reconciliation had taken place (Fujisawa et 
al., 2006). These findings appear homologous to some studies of substituted reconciliation in captive chimpanzees and bonobos (Fraser et al., 2008; Palagi et al., 2004) although other studies did not find such evidence in these species (Clay \& de Waal, 2013; Koski \& Sterck, 2007). As bystander-solicited affiliation seems to be present in some primates despite lacking a stress-reducing effect (Call et al., 2002; McFarland \& Majolo, 2012; Schino \& Marini, 2012), this behaviour may have diverse functions across species and even among groups in different living environments. For instance, many primate studies did not find bystander-solicited contacts had a stressreducing effect in receivers, suggesting that its function may differ among species.

In this respect, while some bystander-solicited affiliation may be driven by empathic tendencies, others may not be strictly altruistic. As well as functioning for substituted reconciliation, bystander-solicited affiliation may reduce punishment risk, increase social rewards, or reduce personal distress, all which can be unrelated to empathy (Batson, 2011). Consolers may also receive benefits through reciprocity, counting on receiving post-conflict affiliation in the future (Watts, 2002). Furthermore, offering affiliation to the victim may reduce potential reactive aggression by the victim, thereby benefiting the actor and the group as a whole (Palagi et al., 2006). Thus, while a consolatory response may be proximately driven by emotional matching, understanding, and an intention to reduce another's negative arousal, the behaviour may have other selfish adaptive functions. The two do not need to be mutually exclusive, and it may be the case that even consolatory contacts may infer benefits to the consoler while also comforting the victim.

From a proximate level, the underlying cognitive and affective processes driving bystander-solicited affiliation, including empathic consolation, remain obscure. This is because features of the observers' behavioural or physiological reaction towards the distressed victim are often unreported, which is crucial to distinguish whether the responder is experiencing personal distress which their affiliation towards the victim can alleviate. In chimpanzees, bystanders have been reported to show an absence of overt signs of distress before approaching distressed individuals, suggesting that either they 
show fast affective extinction rates, or that their responses are not primarily motivated by alleviating their own arousal (de Waal \& Aureli, 1996). However, victim stress or anxiety is typically measured by behavioural indicators as opposed to physiological changes (Fraser et al., 2008; Koski \& Sterck, 2007), which may reveal subtler underlying affective responses to conspecific distress.

In sum, consolation and other forms of bystander-initiated affiliation occur in numerous primates but appear to differ widely in form and function. Using the criteria of observable victim anxiety reduction, lack of obvious direct benefits and a bias towards close social partners (Romero \& de Waal, 2010, consolation has only been observed in a small number of primate species: humans, chimpanzees, bonobos, and Tonkean macaques (Clay \& de Waal, 2013; Fraser et al., 2008; Palagi et al., 2014; Zahn-Waxler \& RadkeYarrow, 1990). Thus, while bystander-solicited affiliation may be relatively more common, consolation appears quite rare, and is potentially linked to higher levels of social tolerance and enhanced emotional sensitivity. Importantly however, while comparing species may show reliable species-differences in social tolerance, there can also be extensive within-species differences in social tolerance (Cronin et al., 2014). Thus far, intergroup comparisons into consolatory tendencies and its relation to social tolerance have not yet been undertaken. Such an investigation may yield important insight into how flexible the expression of empathy can be within the same species and to what extent is influenced by local social and environmental conditions.

\subsection{Targeted helping}

By accurately distinguishing one's own state and needs from those of another, individuals can tailor active prosocial responses to specific situations, helping in a way that meets a recipient's specific requirements (de Waal, 2008). This behaviour is typically termed targeted helping (de Waal, 2008), and requires accurate perspectivetaking of another individual's situation in order to provide an effective, specific response (Yamamoto et al., 2012). Distinguishing empathy-related targeted helping from other 
prosocial responses depends upon whether the action is fine-tuned to an individual's emotional situation (Pérez-Manrique \& Gomila, 2018). Such flexible behaviours have primarily been reported as case studies and anecdotes in the form of rescuing and epimeletic behaviour, including caring for ill or injured individuals and pre-emptive protection (e.g., de Waal, 2019; Pruetz, 2011).

Prosocial behaviour in children has been argued to be motivated by other-oriented concern and inner arousal, as measured by pupil dilation (Hepach et al., 2013). While such comparisons of internal and external responses to the emotions of others have not yet been studied within the same paradigm in primates, the affective basis of helping may be testable to investigate whether there may be an emotional motivation behind one's helping behaviour. For now, we describe observations and experiments looking at examples of targeted helping in primates including case studies and anecdotes of rescuing and epimeletic behaviour.

\subsubsection{Targeted helping in primates}

In primates, helping behaviour is often studied experimentally using food-related paradigms. Despite this, many primates do not tend to show other-regarding preferences under feeding conditions; this includes orangutans (Pongo abelii; Pongo pygmaeus; Amici et al., 2014; Kim et al., 2015), western gorillas, spider monkeys (Amici et al., 2014), cotton-top tamarins (Saguinus oedipus; Cronin et al., 2009), and Japanese macaques (Burkart \& van Schaik, 2013). By comparison, some species have demonstrated mixed tendencies to help others in such conditions; these include capuchin monkeys, bonobos, and chimpanzees, who have all demonstrated both positive (e.g., Claidière et al., 2015; Tan \& Hare, 2013; Yamamoto et al., 2009, 2012) and negative other-regarding preferences in food-related paradigms (e.g., Amici et al., 2014; Burkart \& van Schaik, 2013).

In a seminal study, Yamamoto et al. (2012) studied targeted helping in captive chimpanzees using a tool-reaching paradigm. In this study, the subject needed to 
provide a partner with a specific tool, meaning that visual access to their partner's need was necessary in order to help them. Blocked visual access led to inaccurate helping; however, it was also shown that chimpanzees generally only helped when directly requested by their partner. Rather than understanding another individual's specific need and spontaneously offering the necessary help, the pattern of results suggest that the chimpanzee's helping behaviour may instead be better explained as responding to their partner's direct requests. Nevertheless, Tan et al. (2017) subsequently found that captive bonobos would voluntarily aid unfamiliar bonobos with obtaining food, even when solicitation was not possible. The bonobos also appeared willing to share food with unfamiliar conspecifics to receive social interactions and would even help unfamiliar bonobos reach inaccessible food, provided they were not required to give up their own food (Tan \& Hare, 2013). While bonobos have not exhibited such otheroriented responses on more cognitively demanding tasks (Tan et al., 2015), this result also complements other evidence that suggests bonobos are more tolerant than chimpanzees and outperform them on cooperation tasks when food can be monopolized (Hare et al., 2007). Such findings may explain their willingness to engage with unfamiliar indiviuals in both captivity and the wild to build a wider social network.

Due to methodological constraints, emotion-related helping behaviours are more commonly reported as observational case studies rather than experimental manipulations. For instance, some great apes have been observed putting themselves at risk to help individuals in distress. Pruetz (2011) described a case of a young male chimpanzee assisting an unrelated female unable to carry her infant, despite no signals or indication of distress from either individual. This behaviour was spontaneous, unusual for this male, not repeated over the next eight weeks, and did not appear to provide any benefits. de Waal (2019) described an instance of a dominant male bonobo at the San Diego Zoo who attracted the keeper's attention, apparently to inform them that several young bonobos had fallen into a dry moat and could not get out. Had the moat been filled with water, the juveniles would have drowned as they cannot swim, so the male may have taken pre-emptive action to prevent a dangerous situation. 
Pre-emptive protection may also serve as an epimeletic form of targeted helping (PérezManrique \& Gomila, 2018) with cases of wild chimpanzees providing flexible helping behaviour such as cleaning conspecific's wounds (Boesch, 1992) and assisting moving between trees (de Waal, 2008). Hirata (2009) outlined a variety of occasions where chimpanzee mothers have rescued infants from dangerous circumstances by observing their behaviour and responding accordingly. Pre-emptively helping before a situation has become distressing may represent one of the most advanced forms of empathy, as it would involve understanding imminent risks, relevant consequences, and taking active prosocial steps to prevent them.

Apparent expressions of concern and consolation towards distressed or suffering conspecifics has been observed in great apes and monkeys (Bezerra et al., 2014; Boesch, 1992; Campbell, 2019; de Waal, 2019). Furthermore, proactive helping responses have also occurred despite no clear solicitation or signalling (Pruetz, 2011). Campbell (2019) reported on a wild juvenile male barbary macaque who suffered a severe injury and was fostered by a neighbouring group, who attended to his wounds and groomed him. Similar affiliation towards injured group members has also been seen in wild barbary macaques (Campbell et al., 2016), as well as a wild male common marmoset who appeared to protect a dying female from unrelated individuals and possible predators (Bezerra et al., 2014). Chapman and Chapman (1987) reported on compensatory care offered from a mother towards a juvenile who suffered a traumatic injury and lost his tail. For five months following the injury, the mother nursed and carried the already weaned juvenile. These observations suggest that wild monkeys can exhibit tolerance and epimeletic care towards familiar conspecifics, and possibly towards unfamiliar conspecifics too (Campbell, 2019).

The prosocial motivations underlying primate helping behaviour remain contested. Some researchers have suggested that great ape prosocial behaviour in experimental paradigms instead represents individuals acting on personal gain, given that selfregarding preferences are common among primates (Burkart \& van Schaik, 2013; Cronin et al., 2009). However, some of the cases above, such as helping an injured 
group mate, suggest that more prosocial motivations may also operate in some contexts. Naturalistic observations of food sharing have been reported in wild chimpanzees and bonobos (Samuni et al., 2018; Yamamoto, 2015) and captive bonobos have been shown to voluntarily share their food with others (Krupenye et al. 2019). However, beyond instrumental helping, other-regarding preferences, and food sharing, there lacks a clear programme for systematically studying emotion-related targeted helping behaviour in animals. Further use of naturalistic settings to study these behaviours would help to avoid creating unnecessary anxiety in captive individuals by introducing artificial experimental paradigms.

As a promising direction, as with consolation, social tolerance has been linked with prosociality in animals, including primates (Martin et al., 2021; Palagi et al., 2014). For instance, common marmosets have been reported to exhibit high levels of both proactive prosociality and social tolerance (Burkart \& van Schaik, 2013) and the reviewed research also indicates bonobos to be high in both. This trend has been suggested to relate to extensive cooperation between group members; however, another cooperative breeding primate, cottontop tamarins, do not appear to have the same prosocial preferences as do common marmosets (Cronin et al., 2009). Therefore, while there appears to be link between social tolerance and proactive prosociality further research is needed to understand the degree of variability in this relationship within and between species.

In sum, although systematic observational and experimental data on targeted helping is limited, combined evidence from both experimental and observational studies indicates that some nonhuman primates may be capable of understanding specific needs of others, and they will sometimes intervene accordingly. Systematic data on instrumental helping and perspective-taking indicates that many primates are capable of understanding the needs of others, and this may enable them to provide flexible situation-dependent responses. Current evidence indicates that great apes may be more flexible in their responses than monkeys (Boesch, 1992; Pruetz, 2011) and that 
more complex forms of prosociality may also relate to social tolerance and a species' cooperative tendencies.

\section{Conclusion}

With the progression of animal research has come the understanding that animals and many primates in particular exhibit socioemotional behaviors and processes akin to empathy. Similar to humans, primates appear able to connect with others emotionally and non-emotionally through contingent behaviours such as mimicry, behavioural contagion, and emotional contagion. Some primates can also mentally represent the internal states of others and comprehend that they have different perspectives to their own, which they can use to tailor their own behavioural decisions, based on that knowledge. The most advanced forms of empathic responding in animals, considered to be targeted helping and consolation, currently appear to feature in the social lives of only a subset of species, most notably the great apes and some monkeys, despite other forms of prosocial responding being relatively common.

Some empathy-related responses, particularly consolation, appear to emerge early in life in different species, and remain consistent throughout the lifespan, reflecting personality-like characteristics (e.g., Webb et al., 2017). Instinctive, reflexive responding to others' emotions does not necessarily imply the cognitive understanding of others' affective states and intentions. Yet, sensitivity to peer emotions may be a building block towards more complex manifestations of Theory of Mind and perspective-taking (Seyfarth \& Cheney, 2013). As components of empathy persist through the primate family, natural selection may have favoured individuals that empathise with others as emotional responsiveness facilitates the bonding of strong social relationships and more elaborated forms of cooperation (de Marco et al., 2011; Seyfarth \& Cheney, 2013).

Despite a plethora of studies investigating these individual behaviours, there is no systematic program incorporating multiple empathic components in primates or animals 
in general. A more comprehensive program could investigate how these separate components manifest in practice and whether they co-occur. Further cross-species comparisons on the empathic behaviours described in this chapter can shed light on how the wider empathic phenomena has phylogenetic or convergent evolutionary origins among primates, and how this has resulted in empathy as we know it in humans. There is a notable lack of coverage in some primate species, particularly gibbons despite significant attention on other apes, which may be due to being understudied in many cognitive and emotional aspects. Finally, beyond interspecific variation in primate empathy, the presence of much intraspecific variation indicates a strong prevalence for behavioural flexibility in how our close genetic relatives perceive and respond to the emotions of others.

\section{References}

Adriaense, J. E. C., Koski, S. E., Huber, L., \& Lamm, C. (2020). Challenges in the comparative study of empathy and related phenomena in animals. Neuroscience \& Biobehavioral Reviews, 112, 62-82.

Amici, F., Aureli, F., \& Call, J. (2014). Response facilitation in the four great apes: Is there a role for empathy? Primates, 55, 113-118.

Amici, F., Aureli, F., Visalberghi, E., \& Call, J. (2009). Spider monkeys (Ateles geoffroyi) and capuchin monkeys (Cebus apella) follow gaze around barriers: Evidence for perspective taking? Journal of Comparative Psychology, 123, 368-374.

Amici, F., Visalberghi, E., \& Call, J. (2014). Lack of prosociality in great apes, capuchin monkeys and spider monkeys: Convergent evidence from two different food distribution tasks. Proceedings of the Royal Society B: Biological Sciences, 281, 20141699. 
Arre, A. M., Clark, C. S., \& Santos, L. R. (2020). Do young rhesus macaques know what others see?: A comparative developmental perspective. American Journal of Primatology, 82, e23054.

Aureli, F., Das, M., Verleur, D., \& van Hooff, J. A. R. A. M. (1994). Postconflict social interactions among barbary macaques (Macaca sylvanus). International Journal of Primatology, 15, 471-485.

Baenninger, R. (1997). On yawning and its functions. Psychonomic Bulletin \& Review, 4, 198-207.

Baker, M. A., Cronin, M. J., \& Mountjoy, D. G. (1976). Variability of skin temperature in the waking monkey. The American Journal of Physiology, 230, 449-455.

Batson, C. D. (2011). Empathy-induced altruism: Friend or foe of the common good? In D. R. Forsyth \& C. L. Hoyt (Eds.), For the greater good of all: Perspectives on individualism, society, and leadership (pp. 29-47). Palgrave Macmillan US.

Batson, C. D., Early, S., \& Salvarani, G. (1997). Perspective taking: Imagining how another feels versus imaging how you would feel. Personality and Social Psychology Bulletin, 23, 751-758.

Bezerra, B. M., Keasey, M. P., Schiel, N., \& da Silva Souto, A. (2014). Responses towards a dying adult group member in a wild New World monkey. Primates, 55, 185-188.

Boesch, C. (1992). New elements of a theory of mind in wild chimpanzees. Behavioral and Brain Sciences, 15, 149-150.

Bradley, M. M., Miccoli, L., Escrig, M. A., \& Lang, P. J. (2008). The pupil as a measure of emotional arousal and autonomic activation. Psychophysiology, 45, 602-607. 
Bray, J., Krupenye, C., \& Hare, B. (2014). Ring-tailed lemurs (Lemur catta) exploit information about what others can see but not what they can hear. Animal Cognition, 17, 735-744.

Buchanan, T. W., Bagley, S. L., Stansfield, R. B., \& Preston, S. D. (2012). The empathic, physiological resonance of stress. Social Neuroscience, 7, 191-201.

Burkart, J. M., \& Heschl, A. (2007). Understanding visual access in common marmosets, Callithrix jacchus: Perspective taking or behaviour reading? Animal Behaviour, 73, 457-469.

Burkart, J. M., \& van Schaik, C. (2013). Group service in macaques (Macaca fuscata), capuchins (Cebus apella) and marmosets (Callithrix jacchus): A comparative approach to identifying proactive prosocial motivations. Journal of Comparative Psychology, 127, 212-225.

Burkett, J. P., Andari, E., Johnson, Z. V., Curry, D. C., de Waal, F. B. M., \& Young, L. J. (2016). Oxytocin-dependent consolation behavior in rodents. Science, 351, 375378.

Butovskaya, M. L., Meishvili, N. V., \& Chalyan, V. G. (2015). Redirection of aggression and consolation in hamadryas baboons. Neuroscience and Behavioral Physiology, 45, 417-422.

Call, J., Aureli, F., \& de Waal, F. B. M. (2002). Postconflict third-party affiliation in stumptailed macaques. Animal Behaviour, 63, 209-216.

Call, J., \& Tomasello, M. (2008). Does the chimpanzee have a theory of mind? 30 years later. Trends in Cognitive Sciences, 12, 187-192.

Campbell, L. A. D. (2019). Fostering of a wild, injured, juvenile by a neighbouring group: Implications for rehabilitation and release of Barbary macaques confiscated from illegal trade. Primates, 60, 339-345. 
Campbell, L. A. D., Tkaczynski, P. J., Mouna, M., Qarro, M., Waterman, J., \& Majolo, B. (2016). Behavioral responses to injury and death in wild Barbary macaques (Macaca sylvanus). Primates; Journal of Primatology, 57, 309-315.

Campbell, M. W., \& de Waal, F. B. M. (2011). Ingroup-outgroup bias in contagious yawning by chimpanzees supports link to empathy. PloS One, 6, e18283.

Canteloup, C., Piraux, E., Poulin, N., \& Meunier, H. (2016). Do Tonkean macaques (Macaca tonkeana) perceive what conspecifics do and do not see? PeerJ, 4 , e1693.

Chapman, C. A., \& Chapman, L. J. (1987). Social responses to the traumatic injury of a juvenile spider monkey (Ateles geoffroyi). Primates, 28, 271-275.

Chartrand, T. L., \& Bargh, J. A. (1999). The chameleon effect: The perception-behavior link and social interaction. Journal of Personality and Social Psychology, 76(6), 893-910.

Chotard, H., loannou, S., \& Davila-Ross, M. (2018). Infrared thermal imaging: Positive and negative emotions modify the skin temperatures of monkey and ape faces. American Journal of Primatology, 80, e22863.

Claidière, N., Whiten, A., Mareno, M. C., Messer, E. J. E., Brosnan, S. F., Hopper, L. M., Lambeth, S. P., Schapiro, S. J., \& McGuigan, N. (2015). Selective and contagious prosocial resource donation in capuchin monkeys, chimpanzees and humans. Scientific Reports, 5, 7631.

Clay, Z., \& de Waal, F. B. M. (2013). Bonobos respond to distress in others: Consolation across the age spectrum. PLoS One, 8, e55206.

Clay, Z., Webb, C. E, Romero, T., \& de Waal, F. B. M. (2021). Comparative perspectives of empathy development: Insights from chimpanzees and bonobos. In D. Dukes, A.C. Samson, E. A. Walle (Eds.), The Oxford Handbook of Emotional Development. Oxford University Press. 
Cordoni, G., Palagi, E., \& Tarli, S. B. (2006). Reconciliation and consolation in captive western gorillas. International Journal of Primatology, 27, 1365-1382.

Cronin, K. A., Schroeder, K. K. E., Rothwell, E. S., Silk, J. B., \& Snowdon, C. T. (2009). Cooperatively breeding cottontop tamarins (Saguinus oedipus) do not donate rewards to their long-term mates. Journal of Comparative Psychology, 123, 231241.

Cronin, K. A., van Leeuwen, E. J. C., Vreeman, V., \& Haun, D. B. M. (2014). Populationlevel variability in the social climates of four chimpanzee societies. Evolution and Human Behavior, 35, 389-396.

Cuff, B. M. P., Brown, S. J., Taylor, L., \& Howat, D. J. (2016). Empathy: A review of the concept. Emotion Review, 8, 144-153.

Davila-Ross, M., Menzler, S., \& Zimmermann, E. (2008). Rapid facial mimicry in orangutan play. Biology Letters, 4, 27-30.

Davis, J., Davis, Redshaw, J., Suddendorf, T., Nielsen, M., Kennedy-Costantini, S., Oostenbroek, J., \& Slaughter, V. (2021). Does neonatal imitation exist? Insights from a meta-analysis of 336 effect sizes. Perspectives on Psychological Science, $1-25$.

de Marco, A., Cozzolino, R., Dessì-Fulgheri, F., \& Thierry, B. (2011). Collective arousal when reuniting after temporary separation in Tonkean macaques. American Journal of Physical Anthropology, 146, 457-464.

de Waal, F. B. M. (1988). The communicative repertoire of captive bonobos (Pan paniscus), compared to that of chimpanzees. Behaviour, 106, 183-251.

de Waal, F. B. M. (2007). The 'Russian doll' model of empathy and imitation. In S. Bråten (Ed.), Advances in consciousness research: Vol. 68. On being moved: 
From mirror neurons to empathy (p. 49-69). John Benjamins Publishing Company.

de Waal, F. B. M. (2008). Putting the altruism back into altruism: The evolution of empathy. Annual Review of Psychology, 59, 279-300.

de Waal, F. B. M. (2019). Mama's last hug: Animal emotions and what they tell us about ourselves. W. W. Norton \& Company.

de Waal, F. B. M., \& Aureli, F. (1996). Consolation, reconciliation, and a possible cognitive difference between macaques and chimpanzees. In A. E. Russon, K. A. Bard, \& S. T. Parker (Eds.), Reaching into thought: The minds of the great apes (pp. 80-110). Cambridge University Press.

de Waal, F. B. M., \& Preston, S. D. (2017). Mammalian empathy: Behavioural manifestations and neural basis. Nature Reviews Neuroscience, 18, 498-509.

de Waal, F. B. M., \& van Roosmalen, A. (1979). Reconciliation and consolation among chimpanzees. Behavioral Ecology and Sociobiology, 5, 55-66.

Decety, J., \& Svetlova, M. (2012). Putting together phylogenetic and ontogenetic perspectives on empathy. Developmental Cognitive Neuroscience, 2, 1-24.

Demuru, E., \& Palagi, E. (2012). In bonobos yawn contagion is higher among kin and friends. PLOS ONE, 7, e49613.

Dettmer, A. M., Kaburu, S. S. K., Simpson, E. A., Paukner, A., Sclafani, V., Byers, K. L., Murphy, A. M., Miller, M., Marquez, N., Miller, G. M., Suomi, S. J., \& Ferrari, P. F. (2016). Neonatal face-to-face interactions promote later social behaviour in infant rhesus monkeys. Nature Communications, 7, 11940.

Dezecache, G., Zuberbühler, K., Davila-Ross, M., \& Dahl, C. D. (2017). Skin temperature changes in wild chimpanzees upon hearing vocalizations of conspecifics. Royal Society Open Science, 4, 160816. 
Dimberg, U., \& Thunberg, M. (2012). Empathy, emotional contagion, and rapid facial reactions to angry and happy facial expressions. PsyCh Journal, 1, 118-127.

Dindo, M., Whiten, A., \& de Waal, F. B. M. (2009). In-group conformity sustains different foraging traditions in capuchin monkeys (Cebus apella). PLOS ONE, 4, e7858.

Ebisch, S. J., Aureli, T., Bafunno, D., Cardone, D., Romani, G. L., \& Merla, A. (2012). Mother and child in synchrony: Thermal facial imprints of autonomic contagion. Biological Psychology, 89, 123-129.

Eisenberg, N., Guthrie, I. K., Murphy, B. C., Shepard, S. A., Cumberland, A., \& Carlo, G. (1999). Consistency and development of prosocial dispositions: A longitudinal study. Child Development, 70, 1360-1372.

Feneran, A. N., O’Donnell, R., Press, A., Yosipovitch, G., Cline, M., Dugan, G., Papoiu, A. D. P., Nattkemper, L. A., Chan, Y. H., \& Shively, C. A. (2013). Monkey see, monkey do: Contagious itch in nonhuman primates. Acta DermatoVenereologica, 93, 27-29.

Ferrari, P. F., Visalberghi, E., Paukner, A., Fogassi, L., Ruggiero, A., \& Suomi, S. J. (2006). Neonatal imitation in rhesus macaques. PLOS Biology, 4, e302.

Fraser, O. N., \& Bugnyar, T. (2010). Do ravens show consolation? Responses to distressed others. PLOS ONE, 5, e10605.

Fraser, O. N., Koski, S. E., Wittig, R. M., \& Aureli, F. (2009). Why are bystanders friendly to recipients of aggression? Communicative \& Integrative Biology, 2, 285-291.

Fraser, O. N., Stahl, D., \& Aureli, F. (2008). Stress reduction through consolation in chimpanzees. Proceedings of the National Academy of Sciences, 105, 85578562. 
Fuhrmann, D., Ravignani, A., Marshall-Pescini, S., \& Whiten, A. (2014). Synchrony and motor mimicking in chimpanzee observational learning. Scientific Reports, 4, 17.

Fujisawa, K. K., Kutsukake, N., \& Hasegawa, T. (2006). Peacemaking and consolation in Japanese preschoolers witnessing peer aggression. Journal of Comparative Psychology, 120, 48-57.

Hare, B., Call, J., Agnetta, B., \& Tomasello, M. (2000). Chimpanzees know what conspecifics do and do not see. Animal Behaviour, 59, 771-785.

Hare, B., Melis, A. P., Woods, V., Hastings, S., \& Wrangham, R. (2007). Tolerance allows bonobos to outperform chimpanzees on a cooperative task. Current Biology, 17, 619-623.

Hatfield, E., Cacioppo, J. T., \& Rapson, R. L. (1993). Emotional contagion. Current Directions in Psychological Science, 2, 96-100.

Hepach, R., Vaish, A., \& Tomasello, M. (2013). A new look at children's prosocial motivation. Infancy, 18, 67-90.

Herrmann, E., Hare, B., Call, J., \& Tomasello, M. (2010). Differences in the cognitive skills of bonobos and chimpanzees. PLOS ONE, 5, e12438.

Hess, U., \& Blairy, S. (2001). Facial mimicry and emotional contagion to dynamic emotional facial expressions and their influence on decoding accuracy. International Journal of Psychophysiology, 40, 129-141.

Hirata, S. (2009). Chimpanzee social intelligence: Selfishness, altruism, and the mother-infant bond. Primates, 50, 3-11.

Hopper, L. M., Lambeth, S. P., Schapiro, S. J., \& Whiten, A. (2008). Observational learning in chimpanzees and children studied through 'ghost' conditions. Proceedings of the Royal Society B: Biological Sciences, 275, 835-840. 
loannou, S., Ebisch, S., Aureli, T., Bafunno, D., loannides, H. A., Cardone, D., Manini, B., Romani, G. L., Gallese, V., \& Merla, A. (2013). The autonomic signature of guilt in children: A thermal infrared imaging study. PLOS ONE, 8, e79440.

Ioannou, S., Gallese, V., \& Merla, A. (2014). Thermal infrared imaging in psychophysiology: Potentialities and limits: Thermal infrared imaging in psychophysiology. Psychophysiology, 51, 951-963.

Isern-Mas, C., \& Gomila, A. (2019). Making sense of emotional contagion. HUMANA.MENTE Journal of Philosophical Studies, 12(35), 71-100.

Kano, F., Hirata, S., Deschner, T., Behringer, V., \& Call, J. (2016). Nasal temperature drop in response to a playback of conspecific fights in chimpanzees: A thermoimaging study. Physiology \& Behavior, 155, 83-94.

Kapitány, R., \& Nielsen, M. (2017). Are yawns really contagious? A critique and quantification of yawn contagion. Adaptive Human Behavior and Physiology, 3, 134-155.

Kappeler, P. M. (1993). Reconciliation and post-conflict behaviour in ringtailed lemurs, Lemur catta and redfronted lemurs, Eulemur fulvus rufus. Animal Behaviour, 45, 901-915.

Kim, Y., Martinez, L., Choe, J. C., Lee, D.-J., \& Tomonaga, M. (2015). Orangutans (Pongo spp.) do not spontaneously share benefits with familiar conspecifics in a choice paradigm. Primates; Journal of Primatology, 56, 193-200.

Koski, S. E., \& Sterck, E. H. M. (2007). Triadic postconflict affiliation in captive chimpanzees: Does consolation console? Animal Behaviour, 73(1), 133-142.

Kret, M. E., Tomonaga, M., \& Matsuzawa, T. (2014). Chimpanzees and humans mimic pupil-size of conspecifics. PLoS ONE, 9, e104886. 
Krupenye, C., \& Call, J. (2019). Theory of mind in animals: Current and future directions. WIREs Cognitive Science, 10, e1503.

Kuraoka, K., \& Nakamura, K. (2011). The use of nasal skin temperature measurements in studying emotion in macaque monkeys. Physiology \& Behavior, 102, 347-355.

Laméris, D. W., Berlo, E. van, Sterck, E. H. M., Bionda, T., \& Kret, M. E. (2020). Low relationship quality predicts scratch contagion during tense situations in orangutans (Pongo pygmaeus). American Journal of Primatology, 82, e23138.

Lamm, C., Batson, C. D., \& Decety, J. (2007). The neural substrate of human empathy: Effects of perspective-taking and cognitive appraisal. Journal of Cognitive Neuroscience, 19, 42-58.

Leone, A., Ferrari, P. F., \& Palagi, E. (2014). Different yawns, different functions? Testing social hypotheses on spontaneous yawning in Theropithecus gelada. Scientific Reports, 4, 4010.

Lindegaard, M. R., Liebst, L. S., Bernasco, W., Heinskou, M. B., Philpot, R., Levine, M., \& Verbeek, P. (2017). Consolation in the aftermath of robberies resembles postaggression consolation in chimpanzees. PLoS One, 12, e0177725.

MacLean, E. L., Sandel, A. A., Bray, J., Oldenkamp, R. E., Reddy, R. B., \& Hare, B. A. (2013). Group size predicts social but not nonsocial cognition in lemurs. PLOS ONE, 8, e66359.

MacLean, P. D. (1985). Brain evolution relating to family, play, and the separation call. Archives of General Psychiatry, 42, 405-417.

Mallavarapu, S., Stoinski, T. S., Bloomsmith, M. A., \& Maple, T. L. (2006). Postconflict behavior in captive western lowland gorillas (Gorilla gorilla gorilla). American Journal of Primatology, 68, 789-801. 
Mancini, G., Ferrari, P. F., \& Palagi, E. (2013). In play we trust. Rapid facial mimicry predicts the duration of playful interactions in geladas. PloS One, 8, e66481.

Martin, J. S., Koski, S. E., Bugnyar, T., Jaeggi, A. V., \& Massen, J. J. M. (2021). Prosociality, social tolerance and partner choice facilitate mutually beneficial cooperation in common marmosets, Callithrix jacchus. Animal Behaviour, 173, 115-136.

Massen, J. J. M., \& Gallup, A. C. (2017). Why contagious yawning does not (yet) equate to empathy. Neuroscience \& Biobehavioral Reviews, $80,573-585$.

Massen, J. J. M., Šlipogor, V., \& Gallup, A. C. (2016). An observational investigation of behavioral contagion in common marmosets (Callithrix jacchus): Indications for contagious scent-marking. Frontiers in Psychology, 7.

Massen, J. J. M., Vermunt, D. A., \& Sterck, E. H. M. (2012). Male yawning is more contagious than female yawning among chimpanzees (Pan troglodytes). PLOS ONE, 7(7), e40697.

Matheson, M. D. (1999). Social contact following severe aggression in rhesus macaques (Macaca mulatta): A new test of the consolation hypothesis. International Journal of Primatology, 20, 961-975.

McFarland, R., \& Majolo, B. (2012). The occurrence and benefits of postconflict bystander affiliation in wild Barbary macaques, Macaca sylvanus. Animal Behaviour, 84, 583-591.

Melis, A. P., Call, J., \& Tomasello, M. (2006). Chimpanzees (Pan troglodytes) conceal visual and auditory information from others. Journal of Comparative Psychology, 120, 154-162.

Meltzoff, A. N., \& Moore, M. K. (1977). Imitation of facial and manual gestures by human neonates. Science, 198, 75-78. 
Myowa, M. (1996). Imitation of facial gestures by an infant chimpanzee. Primates, 37, 207-213.

Myowa-Yamakoshi, M., Tomonaga, M., Tanaka, M., \& Matsuzawa, T. (2004). Imitation in neonatal chimpanzees (Pan troglodytes). Developmental Science, 7, 437-442.

Nakayama, K., Goto, S., Kuraoka, K., \& Nakamura, K. (2005). Decrease in nasal temperature of rhesus monkeys (Macaca mulatta) in negative emotional state. Physiology \& Behavior, 84, 783-790.

Norscia, I., Demuru, E., \& Palagi, E. (2016). She more than he: Gender bias supports the empathic nature of yawn contagion in Homo sapiens. Royal Society Open Science, 3, 150459.

Ostner, J., Wilken, J., \& Schülke, O. (2021). Social contagion of affiliation in female macaques. Royal Society Open Science, 8, 201538.

Overduin-de Vries, A. M., Spruijt, B. M., \& Sterck, E. H. M. (2014). Long-tailed macaques (Macaca fascicularis) understand what conspecifics can see in a competitive situation. Animal Cognition, 17, 77-84.

Palagi, E. (2018). Not just for fun! Social play as a springboard for adult social competence in human and non-human primates. Behavioral Ecology and Sociobiology, 72, 90.

Palagi, E., Bertini, M., Annicchiarico, G., \& Cordoni, G. (2020). Mirror replication of sexual facial expressions increases the success of sexual contacts in bonobos. Scientific Reports, 10, 18979.

Palagi, E., Cordoni, G., \& Tarli, S. B. (2006). Possible roles of consolation in captive chimpanzees (Pan troglodytes). American Journal of Physical Anthropology, 129, 105-111. 
Palagi, E., Dall'Olio, S., Demuru, E., \& Stanyon, R. (2014). Exploring the evolutionary foundations of empathy: Consolation in monkeys. Evolution and Human Behavior, 35, 341-349.

Palagi, E., Leone, A., Mancini, G., \& Ferrari, P. F. (2009). Contagious yawning in gelada baboons as a possible expression of empathy. Proceedings of the National Academy of Sciences, 106, 19262-19267.

Palagi, E., Norscia, I., \& Cordoni, G. (2019). Lowland gorillas (Gorilla gorilla gorilla) failed to respond to others' yawn: Experimental and naturalistic evidence. Journal of Comparative Psychology, 133, 406-416.

Palagi, E., Norscia, I., \& Demuru, E. (2014). Yawn contagion in humans and bonobos: Emotional affinity matters more than species. PeerJ, 2, e519.

Palagi, E., Norscia, I., Pressi, S., \& Cordoni, G. (2019). Facial mimicry and play: A comparative study in chimpanzees and gorillas. Emotion, 19, 665-681.

Palagi, E., Paoli, T., \& Tarli, S. B. (2004). Reconciliation and consolation in captive bonobos (Pan paniscus). American Journal of Primatology, 62, 15-30.

Parr, L., \& Waller, B. M. (2006). Understanding chimpanzee facial expression: Insights into the evolution of communication. Social Cognitive and Affective Neuroscience, 1, 221-228.

Parr, L. A. (2001). Cognitive and physiological markers of emotional awareness in chimpanzees (Pan troglodytes). Animal Cognition, 4, 223-229.

Paukner, A., \& Anderson, J. R. (2006). Video-induced yawning in stumptail macaques (Macaca arctoides). Biology Letters, 2, 36-38.

Paukner, A., Suomi, S. J., Visalberghi, E., \& Ferrari, P. F. (2009). Capuchin monkeys display affiliation toward humans who imitate them. Science, 325, 880-883. 
Pérez-Manrique, A., \& Gomila, A. (2018). The comparative study of empathy: Sympathetic concern and empathic perspective-taking in non-human animals. Biological Reviews, 93, 248-269.

Platek, S. M., Critton, S. R., Myers, T. E., \& Gallup, G. G. (2003). Contagious yawning: The role of self-awareness and mental state attribution. Cognitive Brain Research, 17, 223-227.

Plotnik, J. M., \& de Waal, F. B. M. (2014). Asian elephants (Elephas maximus) reassure others in distress. PeerJ, 2, e278.

Premack, D., \& Woodruff, G. (1978). Does the chimpanzee have a theory of mind? Behavioral and Brain Sciences, 1, 515-526.

Preston, S. D., \& de Waal, F. B. M. (2002). Empathy: Its ultimate and proximate bases. Behavioral and Brain Sciences, 25, 1-20.

Prochazkova, E., Prochazkova, L., Giffin, M. R., Scholte, H. S., Dreu, C. K. W. D., \& Kret, M. E. (2018). Pupil mimicry promotes trust through the theory-of-mind network. Proceedings of the National Academy of Sciences, 115, E7265-E7274.

Provine, R. (1992). Contagious laughter: Laughter is a sufficient stimulus for laughs and smiles. Bulletin of the Psychonomic Society, 30, 1-4.

Provine, R. R. (1986). Yawning as a stereotyped action pattern and releasing stimulus. Ethology, 72, 109-122.

Pruetz, J. D. (2011). Targeted helping by a wild adolescent male chimpanzee (Pan troglodytes verus): Evidence for empathy? Journal of Ethology, 29, 365-368.

Reddy, R. B., Krupenye, C., MacLean, E. L., \& Hare, B. (2016). No evidence for contagious yawning in lemurs. Animal Cognition, 19, 889-898. 
Reimert, I., Fong, S., Rodenburg, T. B., \& Bolhuis, J. E. (2017). Emotional states and emotional contagion in pigs after exposure to a positive and negative treatment. Applied Animal Behaviour Science, 193, 37-42.

Romero, T., \& de Waal, F. B. M. (2010). Chimpanzee (Pan troglodytes) consolation: Third-party identity as a window on possible function. Journal of Comparative Psychology, 124, 278-286.

Rymarczyk, K., Żurawski, Ł., Jankowiak-Siuda, K., \& Szatkowska, I. (2018). Neural correlates of facial mimicry: Simultaneous measurements of EMG and BOLD responses during perception of dynamic compared to static facial expressions. Frontiers in Psychology, 9.

Samuni, L., Preis, A., Mielke, A., Deschner, T., Wittig, R. M., \& Crockford, C. (2018). Social bonds facilitate cooperative resource sharing in wild chimpanzees. Proceedings of the Royal Society B: Biological Sciences, 285, 20181643.

Sandel, A. A., MacLean, E. L., \& Hare, B. (2011). Evidence from four lemur species that ringtailed lemur social cognition converges with that of haplorhine primates. Animal Behaviour, 81, 925-931.

Santos, L. R., Nissen, A. G., \& Ferrugia, J. A. (2006). Rhesus monkeys, Macaca mulatta, know what others can and cannot hear. Animal Behaviour, 71, 11751181.

Sato, Y., Hirata, S., \& Kano, F. (2019). Spontaneous attention and psycho-physiological responses to others' injury in chimpanzees. Animal Cognition, 22, 807-823.

Scerif, G., Gomez, J.-C., \& Byrne, R. W. (2004). What do Diana monkeys know about the focus of attention of a conspecific? Animal Behaviour, 68, 1239-1247.

Schino, G., \& Marini, C. (2012). Self-protective function of post-conflict bystander affiliation in mandrills. PLOS ONE, 7, e38936. 
Seyfarth, R. M., \& Cheney, D. L. (2013). Affiliation, empathy, and the origins of theory of mind. Proceedings of the National Academy of Sciences, 110, 10349-10356.

Sonnby-Borgström, M. (2002). Automatic mimicry reactions as related to differences in emotional empathy. Scandinavian Journal of Psychology, 43, 433-443.

Speakman, J. R., \& Ward, S. (1998). Infrared thermography: Principles and applications. Zoology, 101, 224-232.

Tan, J., Ariely, D., \& Hare, B. (2017). Bonobos respond prosocially toward members of other groups. Scientific Reports, 7, 1-11.

Tan, J., \& Hare, B. (2013). Bonobos share with strangers. PLOS ONE, 8, e51922.

Tan, J., Kwetuenda, S., \& Hare, B. (2015). Preference or paradigm? Bonobos show no evidence of other-regard in the standard prosocial choice task. Behaviour, 152, 521-544.

van Berlo, E., Díaz-Loyo, A. P., Juárez-Mora, O. E., Kret, M. E., \& Massen, J. J. M. (2020). Experimental evidence for yawn contagion in orangutans (Pongo pygmaeus). Scientific Reports, 10, 22251.

van den Berg, L. M., Reader, S. M., Goossens, B. M. A., \& Sterck, E. H. M. (2012). An analysis of gaze following to a hidden location in long-tailed macaques (Macaca fascicularis). Behaviour, 149, 1319-1337.

van der Schalk, J., Fischer, A., Doosje, B., Wigboldus, D., Hawk, S., Rotteveel, M., \& Hess, U. (2011). Convergent and divergent responses to emotional displays of ingroup and outgroup. Emotion, 11, 286-298.

van Schaik, C. P., Deaner, R. O., \& Merrill, M. Y. (1999). The conditions for tool use in primates: Implications for the evolution of material culture. Journal of Human Evolution, 36, 719-741. 
Verbeek, P., \& de Waal, F. B. M. (1997). Postconflict behavior of captive brown capuchins in the presence and absence of attractive food. International Journal of Primatology, 18, 703-725.

Want, S. C., \& Harris, P. L. (2002). How do children ape? Applying concepts from the study of non-human primates to the developmental study of 'imitation' in children. Developmental Science, 5, 1-14.

Watts, D. P. (2002). Reciprocity and interchange in the social relationships of wild male chimpanzees. Behaviour, 139, 343-370.

Watts, D. P. (1995). Post-conflict social events in wild mountain gorillas (Mammalia, Hominoidea): II. Redirection, side directed behaviour and consolation. Ethology, 100, 158-174.

Webb, C. E., Romero, T., Franks, B., \& de Waal, F. B. M. (2017). Long-term consistency in chimpanzee consolation behaviour reflects empathetic personalities. Nature Communications; London, 8, 1-8.

Yamamoto, C., Morisaka, T., Furuta, K., Ishibashi, T., Yoshida, A., Taki, M., Mori, Y., \& Amano, M. (2015). Post-conflict affiliation as conflict management in captive bottlenose dolphins (Tursiops truncatus). Scientific Reports, 5, 14275.

Yamamoto, S. (2015). Non-reciprocal but peaceful fruit sharing in wild bonobos in Wamba. Behaviour, 152, 335-357.

Yamamoto, S., Humle, T., \& Tanaka, M. (2009). Chimpanzees help each other upon request. PLOS ONE, 4, e7416.

Yamamoto, S., Humle, T., \& Tanaka, M. (2012). Chimpanzees' flexible targeted helping based on an understanding of conspecifics' goals. Proceedings of the National Academy of Sciences, 109, 3588-3592. 
Zahn-Waxler, C., \& Radke-Yarrow, M. (1990). The origins of empathic concern. Motivation and Emotion, 14, 107-130.

Zentall, T. R. (2003). Imitation by animals: How do they do it? Current Directions in Psychological Science, 12, 91-95. 